\title{
2 European carbon storage resource requirements of climate change mitigation targets
}

3 Yuting Zhang ${ }^{1}$, Christopher Jackson ${ }^{1,2}$, Christopher Zahaky ${ }^{3}$, Azka Nadhira ${ }^{1}$, Samuel Krevor ${ }^{1}$

$4 \quad{ }^{1}$ Department of Earth Science and Engineering, Imperial College London, UK

$5 \quad{ }^{2}$ Department of Earth and Environmental Sciences, University of Manchester, UK

$6 \quad{ }^{3}$ Department of Geoscience, University of Wisconsin-Madison

$7 \quad$ *Correspondence:

8 Yuting Zhang

$9+447446137581$

10 yuting.zhang16@imperial.ac.uk

11

12

13 Peer review statement

14 The paper is a peer-reviewed preprint submitted to EarthArXiv.

15 This preprint has been published in the International Journal of Greenhouse Gas Control.

16

17

18

19

20

21

22

23

24

25

26

27 
- European CCS plans imply >9\% annual growth in injection rates from 2030-2050

- The resource base of either offshore Norway or the UK alone can meet scaleup needs

- Logistic models provide a simple framework to evaluate European $\mathrm{CO}_{2}$ storage scale-up

- Growth models can be used to constrain output from energy systems models

As a part of climate change mitigation plans in Europe, $\mathrm{CO}_{2}$ storage scenarios have been reported for the United Kingdom and the European Union with injection rates reaching $75-330 \mathrm{MtCO}_{2} \mathrm{yr}^{-1}$ by 2050 .

38 However, these plans are not constrained by geological properties or growth rates with precedent in

39 the hydrocarbon industry. We use logistic models to identify growth trajectories and the associated

40 storage resource base consistent with European targets. All of the targets represent ambitious growth,

41 requiring average annual growth in injection rates of $9 \%-15 \%$ from $2030-2050$. Modelled plans are

42 not constrained by $\mathrm{CO}_{2}$ storage availability and can be accommodated by the resources of offshore UK 43 or Norway alone. Only if the resource base is significantly less, around $10 \%$ of current estimates, does 44 storage availability limit mitigation plans. We further demonstrate the use of the models to define 2050 rate targets within conservative bounds of both growth rate and storage resource needs.

47 Keywords: $\mathrm{CO}_{2}$ storage; Logistic modelling; Storage resource requirement; Growth rates; Mitigation 48 targets; Europe 


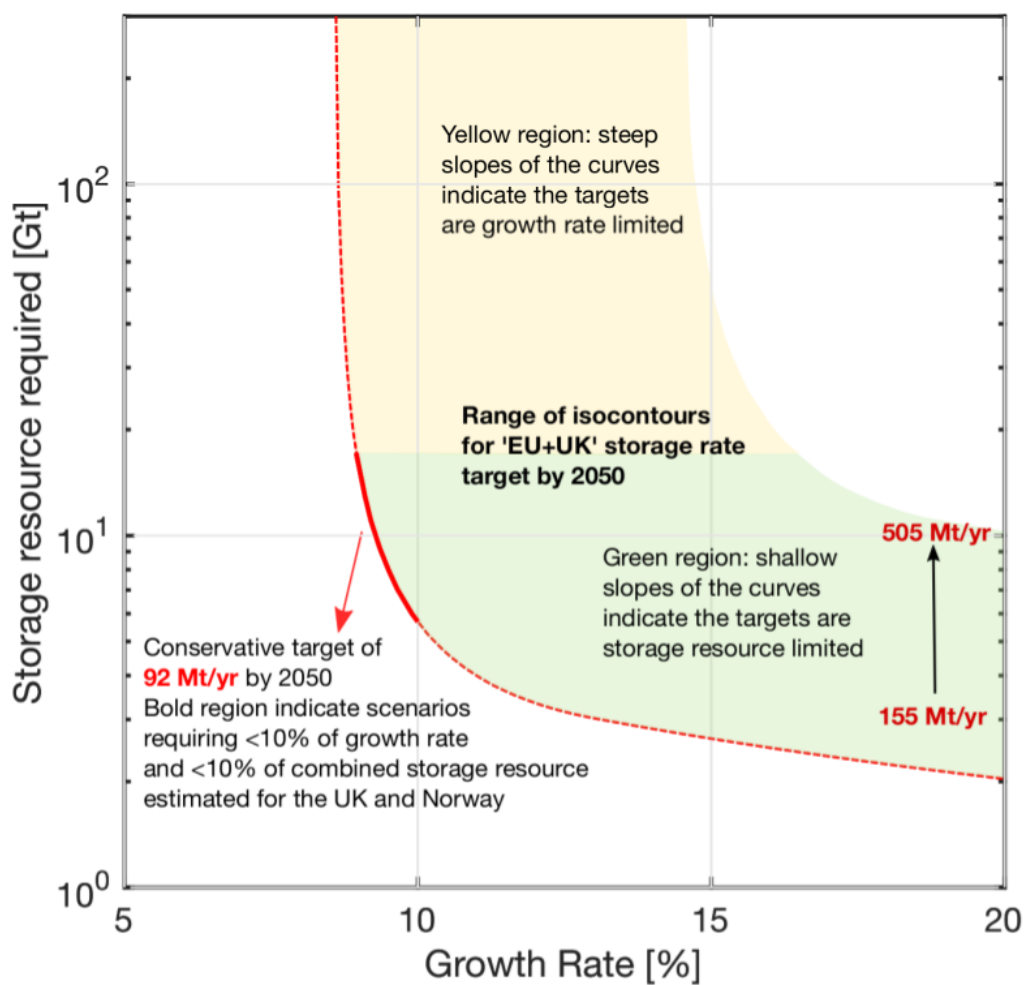


Very large-scale carbon capture and geological storage (CCS) may be needed to mitigate climate change $\mathrm{e}^{1,2,3,4,5,6,7}$. Assessments of technological pathways available for limiting global warming to less than $1.5^{\circ} \mathrm{C}$ and $2^{\circ} \mathrm{C}$ suggest that $\mathrm{CO}_{2}$ may be injected underground at rates of $10 \mathrm{Gt}$ per year by mid-century, and that $>1000 \mathrm{Gt}$ will need to have been stored by the end of the century? ${ }^{7}$ This is a similar scale to that of the fluids currently being handled by the hydrocarbon industry globally ${ }^{8}$. The European Union (EU) and the United Kingdom (UK) have a commensurate scale of carbon storage in their climate change mitigation plans including scenarios with combined over $500 \mathrm{Mt} \mathrm{CO}_{2}$ injected

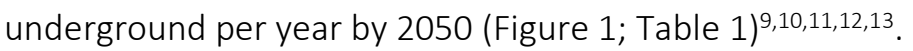

There are several indications that this scale of deployment is achievable. There are currently 26 facilities around the world with injection rate capacities ranging from $0.5-2 \mathrm{Mt} \mathrm{yr}^{-1}$ demonstrating the large-scale use of CCS technology ${ }^{14}$. Within Europe, there are two operational CCS facilities in Norway (Sleipner and Snøhvit) and one in Croatia; these three projects have a combined injection capacity of $1.7 \mathrm{Mt} \mathrm{yr}^{-114,15}$. Global estimates of storage resources suggest there are vast volumes of pore space underground suitable for sequestering $\mathrm{CO}_{2}$. We adopt the definition of resources from the classification framework of the $\mathrm{CO}_{2}$ Storage Resources Management System ${ }^{16}$. Recent evaluations identify a storage resource base between $10,000-30,000 \mathrm{Gt}$ available worldwide ${ }^{17,18,19}$. This is potentially $3-10$ times more than the maximum global storage resources needed to support the most aggressive $\mathrm{CO}_{2}$ storage scaleup trajectories identified by the IPCC, limiting global warming to less than $2^{\circ} \mathrm{C}^{20}$. The combined estimate of effective storage resources in Europe is $260 \mathrm{Gt}$, including resources distributed among EU member states for both onshore and offshore ( $88 \mathrm{Gt}$ in total), and offshore UK (78 Gt) and Norway (94 Gt; Figure 1) 19,21,22,23,24,25. However, concerns over onshore storage of $\mathrm{CO}_{2}$ in the $\mathrm{EU}$, e.g., by the European Commission ${ }^{26}$, could limit its use to offshore resources alone (19 Gt, or $22 \%$ of the total, for EU member states $21,27,28,29)$.

At the same time, there are significant uncertainties in the scaleup of CCS to achieve climate change mitigation targets. It has been recognised that current integrated assessment models (IAMs) that identify scaleup trajectories for $\mathrm{CO}_{2}$ storage contain gaps in the representation of realistic consumption of depletable natural resources ${ }^{30,31}$. The constraints used in IAMS to determine deployment projections of technologies are predominantly costs. For CCS, while some IAMs do include an upper limit on available storage resources or a maximum injection rate, these are only single-value constraints ${ }^{5,32}$. As a comparison, the upscaling of other low-carbon technologies i.e., solar and wind technologies in IAMs are constrained by a historical annual growth limit i.e., 10\% $\mathrm{yr}^{-1} 32$.

99 Zahasky and $\mathrm{Krevor}^{20}$ have further pointed out that estimates of storage resources based on 
100 geological features alone are inherently uncertain and can range in up to two orders of magnitude. As

101 a result, geological considerations alone are insufficient to describe actual development trajectories

102 of CCS. Rather, there is a range of factors that could potentially limit the growth of subsurface storage

103 sites, including the geophysical limit to the injectivity rate of $\mathrm{CO}_{2}$ as a result of the pressurisation of

104 the reservoir in repose to injection, latencies in project development, i.e., the discovery and appraisal

105 of suitable injection sites, and a combination of economic, social, and political constraints

$10633,34,35,36,37,38,39,40,41$. The amount of $\mathrm{CO}_{2}$ stored underground in IAMs or regional or national energy

107 systems models does not reflect attributes from these potentially limiting processes ${ }^{42}$.

108 In this work, we make use of the logistic growth model - a simple framework that has been

109 widely used in analogous industries, like the oil and gas industry, to investigate plausible growth

110 trajectories for the scaleup of $\mathrm{CO}_{2}$ storage in the UK and the EU that are identified in climate change

111 mitigation roadmaps. Under the logistic modelling framework, the impacts of geophysical and

112 engineering limitations to subsurface resource management are combined with non-geological

113 factors like securing finance and navigating governmental regulations to determine deployment

114 trajectories ${ }^{20,43,44}$. Furthermore, this model is particularly useful for understanding the

115 interconnections between early growth rate, the duration of sustained exponential growth, and the

116 size of the resource base required to support that growth, a relationship not currently captured by

117 the energy systems models and IAMs. While mature industries can make use of data from the

118 historical development to use logistic models predictively, this is not possible for the emerging $\mathrm{CO}_{2}$

119 storage industry. Rather, we use the models to apply a range of storage resource constraints and to

120 identify limiting features - minimum growth rates supported by the available storage resource base

121 that is consistent with $\mathrm{CO}_{2}$ storage rate targets published in climate change mitigation plans for the

122 UK and the European Union. This allows us to place these plans in the context of historical growth in

123 analogous technologies, the estimates for the $\mathrm{CO}_{2}$ storage resource base in each region, and to

124 specify quantitatively the role that the UK and Norwegian continental shelf will need to play as a

125 storage hub for emissions from the EU. Additionally, we show how the framework can be used to

126 identify storage scaleup scenarios subject to conservative limitations of rates of growth and storage

127 resource requirements. 


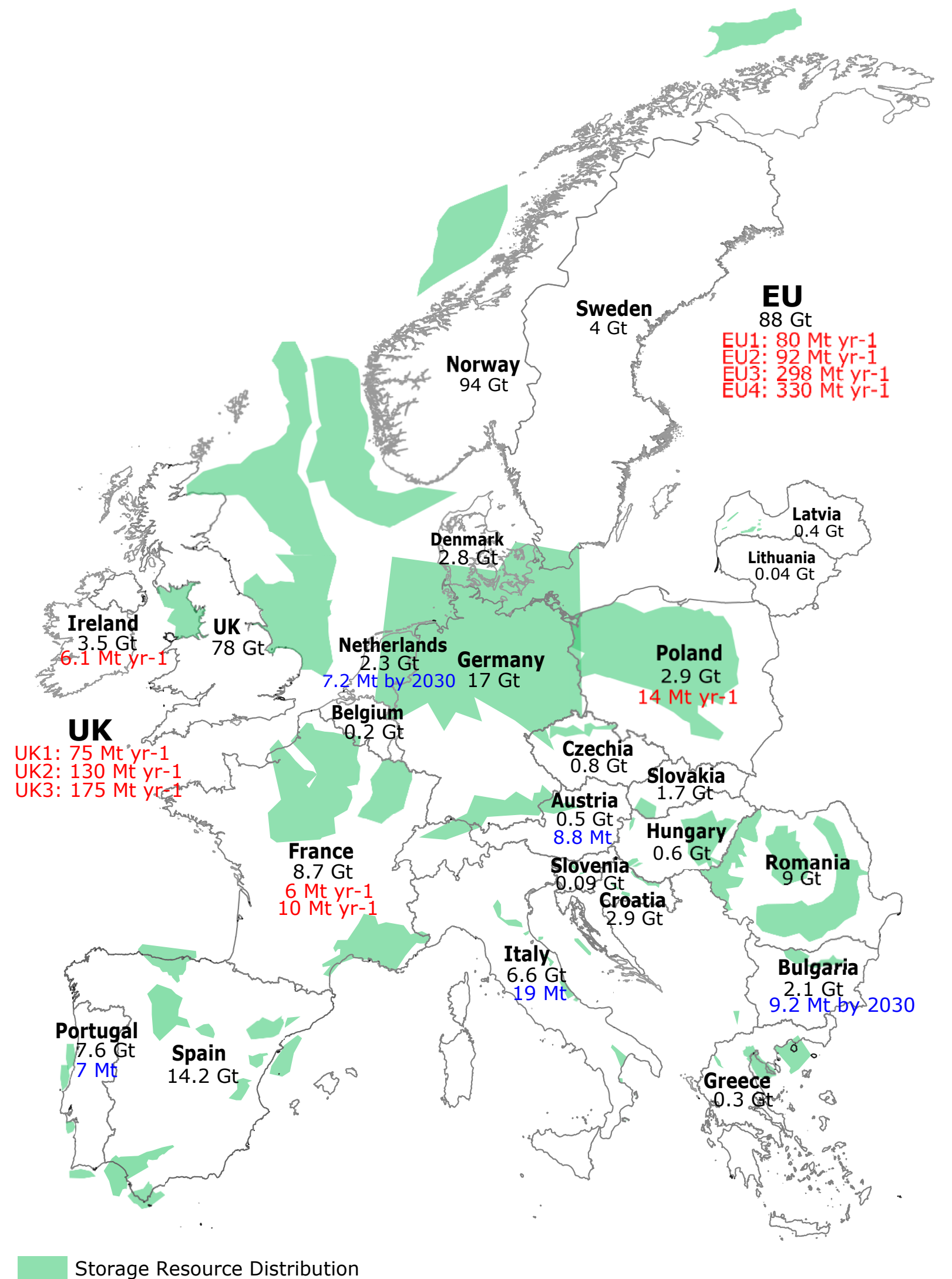
Storage Resource Distribution 
130 Figure 1: A map of Europe showing the distribution of storage resources and the regional/national

$131 \mathrm{CO}_{2}$ storage targets for 2050 unless indicated otherwise (storage rate targets in red and cumulative

132 storage targets in blue). Green polygons indicate major storage resource locations comprising

133 predominately of saline aquifers. The total effective storage resource estimated to be available in

134 Europe is $260 \mathrm{Gt}$. Of this estimate, $66 \%$ is located offshore of UK and Norway. A total of 88 Gt of

135 effective storage resources is available among Member States of the EU, however, only $22 \%$ is located

136 offshore.

137

\begin{tabular}{c|c} 
Storage Scenario & Target $\left(\mathrm{MtCO}_{2} \mathrm{yr}^{-1}\right)$ \\
\hline EU1 & 80 \\
EU2 & 92 \\
EU3 & 289 \\
EU4 & 330 \\
UK1 & 75 \\
UK2 & 130
\end{tabular}

138 Table 1: A summary of carbon storage deployment scenarios showing the anticipated annual storage

139 rates of $\mathrm{CO}_{2}$ in 2050 in the $\mathrm{EU}^{9,13}$ and the $\mathrm{UK}^{11,12}$.

1412 METHODS

$142 \quad 2.1$ Identifying resources, targets, and plans of $\mathrm{CO}_{2}$ storage in the European Union

143 The majority of the storage potential of EU member states was estimated by the EU

144 GeoCapacity consortium ${ }^{21}$. Of the three reservoir types analyzed by the EU GeoCapacity consortium,

145 which are deep saline aquifers, depleted hydrocarbon fields and unmineable coal beds, storage

146 resources in deep saline aquifers constitute $85 \%$ of the total estimate for the EU ( $88 \mathrm{Gt}$ ). As a result,

147 the approach and assumptions used to estimate storage resources in deep saline aquifers are the

148 most significant. In the GeoCapacity database, estimates of storage resources in deep saline aquifers

149 are based on formulas provided by Bachu et al. ${ }^{45}$. The initial potential storage sites and sealing units

150 are determined through a screening process using a cut-off criterion. Subsequently, the effective

151 estimates of storage resources for each structural or stratigraphic trap are determined volumetrically

152 by applying a storage efficiency factor. In GeoCapacity's assessment, they have used trap specific 
153 storage efficiency factors which vary depending on the assumption of whether the aquifer system is 154 open/semi-closed or closed. For their conservative estimates of storage resources in each member 155 state, they typically use a reduced storage efficiency factor between $1 \%-20 \%$ depending on the type 156 of aquifer system (open or closed) ${ }^{21}$. We have reported here the sum of their conservative estimates 157 rather than the optimistic estimate that uses a higher efficiency factor for each basin. Other reports 158 provided the effective storage resource estimate for Sweden, Portugal, Austria and Ireland using a 159 similar approach ${ }^{22,24}$. As a result, a total conservative effective storage resource estimate of $88 \mathrm{Gt}$ in 160 the EU (the member states, not including offshore UK or Norway) has been identified. Of this 161 estimate, $19 \mathrm{Gt}$ is available offshore of EU member states and the rest is located onshore $26,27,28,29$. 162 Figure 1 displays a map of Europe summarising the national and regional targets, and the storage 163 resource available in the indicated region or country. For EU member states of Estonia, Finland,

164 Malta, Cyprus, and Luxembourg there are no indications of national targets, storage resource 165 estimations, or CCS development. We have not included the storage resource available offshore of 166 the UK in the $88 \mathrm{Gt}$ estimate as the UK has officially left the EU in 2020. Therefore, our analysis of the 167 EU only refers to the remaining 22 member states. The European Commission strategic long-term report, 'A Clean Planet for All', outlined the 169 decarbonization pathways for the EU to achieve net-zero commitments ${ }^{9}$. In this report, three $\mathrm{CO}_{2}$ 170 storage targets stating that in 2050, injection rates of 80, 92, and $298 \mathrm{MtCO}_{2} \mathrm{yr}^{-1}$ will be necessary to 171 limit warming to $2{ }^{\circ} \mathrm{C}$. Another decarbonization scenario was created by Shell International B.V for the 172 entire world, but identifying emissions reductions associated with particular geographic regions. In 173 Europe, the Shell Sky Scenario in 2018 anticipates an even more ambitious storage rate target of 330 $174 \mathrm{MtCO}_{2} \mathrm{yr}^{-1}$ for $2050^{13}$. These four annual storage rate targets were determined based on the EU28 175 prior to the exit of the UK from the EU and are subsequently referred to as EU1-4 (Fig. 1; Table 1). To 176 date, there is one operational CCS facility and 13 planned CCS facilities in the EU by eight member states of Ireland, France, Belgium, Croatia, Italy, Sweden, Denmark and the Netherlands ${ }^{14}$. From this data, we analyse a group of scenarios that we refer to as the 'EU Member State 179 Scenarios'. With the EU scenarios, we determine a range of growth rates and the necessary storage 180 resource requirements needed to meet EU-wide storage rate targets. We place this in the context of 181 storage resources identified within EU states without the contribution from the UK. As described in 182 subsequent sections, we then evaluate resource use across borders with the UK and Norway and 183 examine the potential for the North Sea alone to accommodate storage demands from the EU given 184 that a significant proportion of the EU storage resource base is located onshore. 
187 Change Act ${ }^{46}$. With this, the UK became the world's first major economy to pass a law requiring a 188 reduction in greenhouse gas emissions by $80 \%$ compared to 1990 levels by $2050^{47}$. Carbon capture 189 and storage has been identified by the UK parliament as a critical technology to facilitate the nation's 190 climate commitments. Similar to the EU, three storage rate targets have been identified; 75 , 130, or $191175 \mathrm{MtCO}_{2} \mathrm{yr}^{-1}$ by $2050^{47,11,12}$. These three storage rate targets are hereafter referred to as UK1-3 192 respectively (Fig. 1; Table 1).

Although the UK does not currently have an operating $\mathrm{CO}_{2}$ storage facility, four industrial

194 clusters have been announced, which aim to reach a storage rate of $10 \mathrm{MtCO}_{2} \mathrm{yr}^{-1}$ by $2030^{10}$. Storage 195 resources for the UK are mostly located in the UK North Sea and the East Irish Sea. An inventory of

196579 sites has been compiled with an estimated combined storage resource of $78 \mathrm{Gt}^{23}$. These

197 resources include basin scale formations like the open saline aquifers in the Triassic Bunter Sandstone

198 Formation in the Southern North Sea, the Forties and Captain Sandstone formations in the Central

199 North Sea. Moreover, low pressure depleted gas fields such as the Ormskirk sandstone and the

200 Hamilton gas field in the East Irish Sea and the Leman sandstone in the Viking gas field both have

201 significant storage potential. Overall, significant development opportunities have been identified to

202 be present in both saline aquifers and depleted oil and gas fields sea that are within proximity to UK's

203 major emission sources in the UK North Sea and the East Irish Sea ${ }^{23}$.

204 In this study, we will evaluate a group of scenarios we refer to as the 'UK Domestic Scenarios' 205 and identify growth rates and the storage resource requirements for UK storage targets. We also 206 evaluate the capability of the UK carbon storage resource to act as a regional CCS hub, servicing 207 additional storage needs from the EU in a group of scenarios we refer to as 'EU + UK Scenarios'. We 208 identify a range of annual growth rates and the necessary storage resource base required to achieve 209 these scenarios.

2102.3 Identifying carbon dioxide storage resources in Norway

211 Norway has played a central role in the demonstration of industrial-scale $\mathrm{CO}_{2}$ storage. The

212 Norwegian government, from as early as 1989, identified CCS as a key innovation technology to

213 reconcile ambitious climate targets with the growing emissions from the country's hydrocarbon

214 industry ${ }^{48}$. There are two operating $\mathrm{CO}_{2}$ storage projects in Norway, Sleipner and Snøhvit, which have 215 been operating since 1996 and 2008, respectively. A new full-scale CCS project called Longship has 216 been announced in 2020 and aims to begin operation by 2024 to further help Norway meeting its 217 climate targets ${ }^{14}$. 
As a result of the relatively small greenhouse emissions originating in Norway, in this analysis,

219 we only consider storage resources as potentially contributing to the EU and UK climate change

220 mitigation targets. Similar to the UK, a vast quantity of resources for $\mathrm{CO}_{2}$ storage $(94 \mathrm{Gt}$ ) is available

221 offshore Norway ${ }^{19}$. Formations of Bryne and Sandnes, Utisra and Skade, and Sognefjord Delta have

222 been identified to contribute most of the storage resource potential for saline aquifers. Within

223 petroleum provinces, the main contribution to the storage resource comes from the Frigg Field in the

224 Frigg-Hemidal Formation aquifer ${ }^{25}$. The storage resources located offshore of Norway is considered

225 the most prospective region for geologic storage of $\mathrm{CO}_{2}$ in Europe ${ }^{49}$ and could play a significant role in

226 offsetting EU-wide industrial emissions. Here, we explore the extent to which the Norwegian storage

227 resources enhance the viability of large-scale $\mathrm{CO}_{2}$ storage within Europe, combining mitigation targets

228 from the EU and UK.

Consumption of finite natural resources often follows a pattern starting with a period of

231 exponential growth (annual growth at a constant rate) and subsequently a slowdown in the early

232 growth rate or even a decline as market conditions shifts or resource availability declines. As a result,

233 S-shaped curves are commonly used to describe the cumulative exhaustion of a resource as opposed

234 to linear or J-shaped exponential models which assume indefinite resource consumption ${ }^{20}$. Several

235 curve-fitting models exist to describe the S-Shaped pattern, but the logistic model is the most

236 widespread. The logistic model has been widely used to predict peak production in oil and coal

237 consumption, and projecting long-term trends in energy systems, infrastructure, and technology

238 development ${ }^{50,51,52,53,54}$

Recently, the logistic model was applied to the analysis of global carbon storage resources ${ }^{20}$.

240 In this context, the model can be used to approximate the relationship between the growth needed

241 to achieve near-term scaleup targets and the resource base that would be required to support that

242 growth which is key for understanding the deployment trajectory of CCS. Thus, another reason we do

243 not use linear or exponential models here is that they cannot capture the relationship between early

244 rates of growth and the available storage resource base.

As aforementioned, a variety of logistic-like curve-fitting models exist, i.e., Gaussian, and

246 normal curves. The differences between these models are significant in their ability to fit existing data

247 or when used to predict future production and peak years ${ }^{52,55}$. However, our purpose here is to

248 explore a range of regional short-term growth trajectories of CCS that are dependent on fixed

249 constraints of storage resources available ${ }^{19}$. A modelling approach developed by Ringrose and Meckel 
made use of historical rates of hydrocarbon well construction in major oil and gas provinces to

251 demonstrate potential development trajectories of global cumulative $\mathrm{CO}_{2}$ injection ${ }^{56}$. They reached similar conclusions as to the analysis of global storage resources and growth trajectories as Zahasky \& Krevor $^{20}$ despite the distinct approaches. and storage rate, $Q(t)$ [ $\left.\mathrm{GtCO}_{2} \mathrm{yr}^{-1}\right]$ of $\mathrm{CO}_{2}$ sequestration as a function of time, $t$ [yr]. The curves are initially exponential, characterised by an early annual growth rate, $r$ [yr-1]. As the peak time, $t_{p}[y r]$, is approached, growth rates decline and are then negative until the storage resource amount, $C$ [Gt], is approached.

$P(t)=\frac{c}{1+\exp \left(r\left(t_{p}-t\right)\right)}$

$260 \quad Q(t)=\frac{C \cdot r \cdot \exp \left(r\left(t_{p}-t\right)\right)}{\left(1+\exp \left(r\left(t_{p}-t\right)\right)\right)^{2}}$

261 An inflection point in the rate time series occurs in year $t_{n}$ given by

$t_{n}=t_{p}-\ln (2+\sqrt{3}) / r$

We take the inflection point to represent the time at which growth begins to deviate significantly below exponential growth. This occurs when approximately $20 \%$ of the resource base is used.

Equation 1 and 2 describe a simple, three-parameter symmetric logistic model, with equal growth and decline trajectories. In practice, symmetry only occurs under a rare combination of circumstances including undisturbed resource exploration for new reserves, consistent economic impetus, limited innovation in resource exploration, and eventually exhaustion of the resource. Asymmetric growth profiles frequently occur, e.g., due to innovation in resource use or decline in market demand ${ }^{50,52}$. However, this is not a particular weakness of the model for our purpose. Due to the lack of historical CCS development, this model is not used to predict likely trajectories, but rather to identify constraints of minimum sustained growth rates required to meet climate change mitigation targets, and the minimum associated resource base needed to support those trajectories ${ }^{20}$. interlink between the growth pattern and the physical quantity of the resources available. In other words, the growth trajectory used to achieve a certain storage target is dependent on both the size of the storage resource base and the storage rate target (or cumulative target) in a given year. Sustained 
annual growth in injection rates is dependent on a large enough resource base so that limits to growth imposed by the geology, or the practicalities of exploiting ever more marginal sites, will not be encountered. As a result, a key feature of the logistic model is the inclusion of the tradeoff between initial annual growth rates and storage resource requirements in the definition of growth trajectories.

We numerically solve Equations 1 and 2 to meet climate change mitigation targets for a region. This identifies rate and cumulative storage trajectories that meet proposed plans. Iterating over a range of parameter space of storage resource requirement and initial (exponential) annual growth rate allows us to identify the scenarios over which these plans may be achieved. From this, minima in the initial growth rate that is supported by the maximum storage resource available can also be identified.

The logistic modelling framework is ultimately a statistical model and comes with associated limitations. First, we avoid using the model for monitoring targets that are earlier than 2050; early

290 growth rates in technology often fluctuate dramatically and the model does not include any

291 exogenous economic or political factors that could impact near-term trajectories of $\mathrm{CO}_{2}$ storage rates.

292 Second, the lack of data for storage resources, or deployment plans for CCS in some regions means

293 that there is a limit to the spatial resolution that can be achieved, e.g., we did not find it useful in 294 application to most individual EU member states. Finally, we do not consider trajectories where the 295 inflection point (the time at which growth falls below the exponential trend) occurs before 2050. If 296 trajectories begin to decline prior to 2050, due to an unexpected severe limitation in storage resource 297 availability, CCS might not be considered by major industry players as a feasible long-term option.

298 Therefore, we add a constraint to all models that inflection points of storage rates must occur post2992050.

3002.5 Model for the European Union targets and the domestic United Kingdom targets

A schematic showing constraints applied to the logistic model for the EU and UK scenarios is

302 shown in Figure 2. The EU member state model is constrained by CCS activities located among EU

303 member states (constraint 1 in Figure 2) and the four 2050 storage rate targets from the scenarios

304 EU1 $\left(80 \mathrm{MtCO}_{2} \mathrm{yr}^{-1}\right)$, EU2 (92 $\left.\mathrm{MtCO}_{2} \mathrm{yr}^{-1}\right)$, EU3 (298 $\left.\mathrm{MtCO}_{2} \mathrm{yr}^{-1}\right)$ and EU4 (330 MtCO $\mathrm{yr}^{-1}$; constraint 2

305 in Figure 2). Similar to the EU member state scenarios, two standard constraints are applied to the 306 modelling for the domestic UK scenarios. The constraints are 1) cumulative storage reached by 2030 307 based on planned facilities in the UK, and 2) storage rate targets of UK1 (75 MtCO $\left.\mathrm{yr}^{-1}\right)$, UK2 (130 $\left.308 \mathrm{MtCO}_{2} \mathrm{yr}^{-1}\right)$ and UK3 $\left(175 \mathrm{MtCO}_{2} \mathrm{yr}^{-1}\right)$. The modelled scenarios identify a group of minimum growth rates supported by the maximum storage resource available ( $88 \mathrm{Gt}$ for the EU or $78 \mathrm{Gt}$ for the UK) to 
meet the storage targets of the respective region. However, $\mathrm{CO}_{2}$ storage resource assessment is also

311 uncertain to over an order of magnitude ${ }^{19}$. Thus, an additional conservative group of higher growth

312 scenarios that depend on only $10 \%$ of the currently identified storage resources are also identified.

313 The inflection year of each growth rate curve indicates the duration of exponential growth since 2030.

314 In Figure 2, we use a solid line for the part of the trajectory where storage rate growth is close to

315 exponential. Beyond the inflection year, the trajectory is dashed to emphasise that these are not

316 predictive growth trajectories but rather are used to identify the resource base required to support

317 the early growth.

318

319 Figure 2: Schematic plot illustrating the key constraints and features of the logistic growth model.

320 Cumulative $\mathrm{CO}_{2}$ storage is shown in red (Equation 1) and the annual injection rate in blue (Equation

321 2). Black dots indicate the cumulative storage from existing or planned CCS development within a

322 region. Note that the plot is illustrative, so numbers are not included for the vertical axes, but curves

323 are shown for plots with logarithmic vertical axes.
2.6 Model for the UK + EU targets

To evaluate the potential of $\mathrm{CO}_{2}$ storage resources located in the North Sea to fulfil the combined storage needs of the UK and EU, the following constraints are used (Figure 3): first, CCS development to establish the initial average growth rates in Europe are assembled based on existing or planned projects announced by EU member states that are taking place in the North Sea region, including offshore Norway and the UK. Second, we evaluate 12 storage scenarios (constraint 2 in 
330 Figure 3) combining the three UK scenarios from the UK Committee on Climate Change ${ }^{11}$ and the four

331 EU scenarios from the European Commission and Shell ${ }^{9,13}$. Furthermore, growth trajectories

332 subjected to $10 \%$ of storage resources available in the UK, Norway and the combined storage

333 resource of the UK and Norway are explored.

334

335

336

337

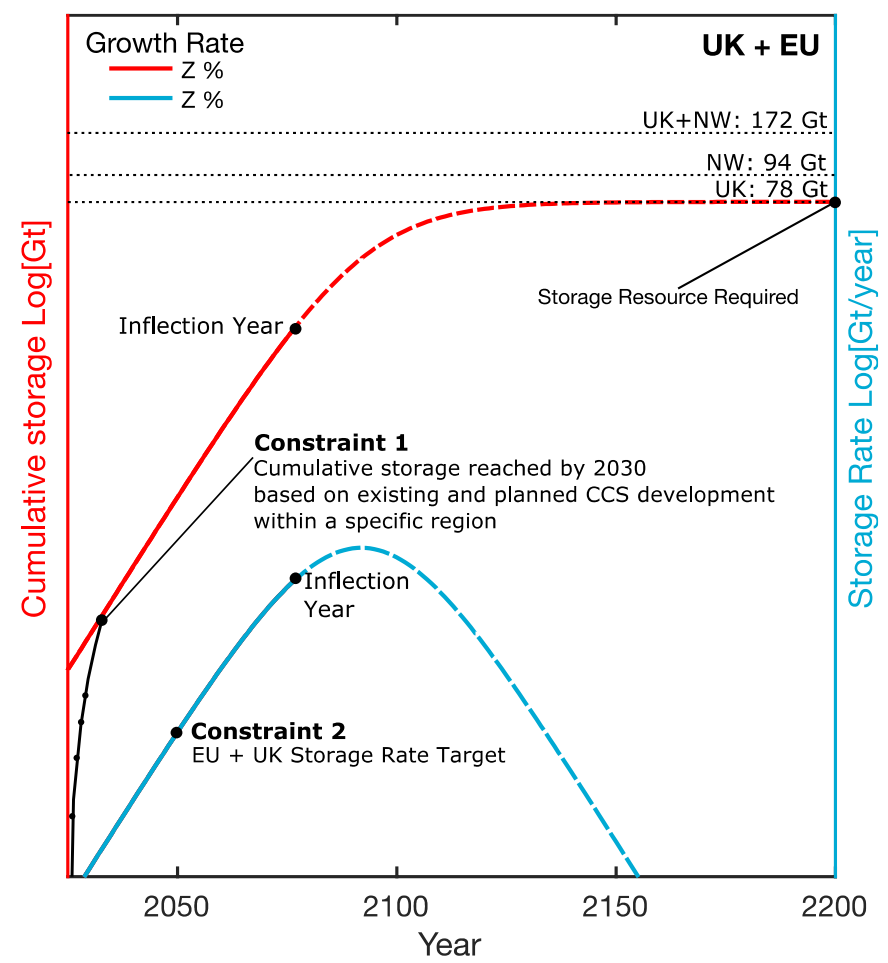

Figure 3: Schematic plots of analysis for the 'EU + UK Scenarios' illustrating each constraint used on an exemplary growth trajectory of Z\%. Note that the plot is illustrative, so numbers are not included for the vertical axes, but curves are shown for plots with logarithmic vertical axes.

\begin{tabular}{|c|c|c|c|c|c|}
\hline \multicolumn{2}{|c|}{ 'EU + UK’ Scenarios } & \multicolumn{4}{|c|}{ UK Storage needs } \\
\hline & & UK1: $75 \mathrm{Mt} \mathrm{yr}^{-1}$ & UK2: $130 \mathrm{Mt} \mathrm{yr}^{-1}$ & UK3: $175 \mathrm{Mt} \mathrm{yr}^{-1}$ & \\
\hline \multirow{2}{*}{$\begin{array}{c}\text { EU member } \\
\text { state }\end{array}$} & EU1: $80 \mathrm{Mt} \mathrm{yr}^{-1}$ & $155 \mathrm{Mt} \mathrm{yr}^{-1}$ & $210 \mathrm{Mt} \mathrm{yr}^{-1}$ & $255 \mathrm{Mt} \mathrm{yr}^{-1}$ & Group A \\
\hline & EU2: $92 \mathrm{Mt} \mathrm{yr}^{-1}$ & $167 \mathrm{Mt} \mathrm{yr}^{-1}$ & $222 \mathrm{Mt} \mathrm{yr}^{-1}$ & $267 \mathrm{Mt} \mathrm{yr}^{-1}$ & Group B \\
\hline \multirow{2}{*}{$\begin{array}{l}\text { storage } \\
\text { needs }\end{array}$} & EU3: $298 \mathrm{Mt} \mathrm{yr}^{-1}$ & $373 \mathrm{Mt} \mathrm{yr}^{-1}$ & $428 \mathrm{Mt} \mathrm{yr}^{-1}$ & $473 \mathrm{Mt} \mathrm{yr}^{-1}$ & Group C \\
\hline & EU4: $330 \mathrm{Mt} \mathrm{yr}^{-1}$ & $405 \mathrm{Mt} \mathrm{yr}^{-1}$ & $460 \mathrm{Mt} \mathrm{yr}^{-1}$ & $505 \mathrm{Mt} \mathrm{yr}^{-1}$ & Group D \\
\hline
\end{tabular}

338 Table 2: The 'EU + UK' scenarios including the combined storage rate in 2050 between the four EU

339 scenarios and the three UK scenarios. Each group contains combinations of growth scenarios of one 
340 EU storage target with all the UK targets. The colour of each target scenario corresponds to

341 isocontours in Fig.9.

342 2.7 Trade-off between annual growth rate and storage resource requirements

343 In the logistic model, there is a relationship between the initial annual growth in injection

344 rates, the duration of near-exponential growth, and the storage resource required. This is suggestive

345 of the real-world relationships between growth trajectories and storage resources. The initial

346 exponential phase of growth can be considered a time period during which growth limitations due to

347 the finite nature of the resource do not impinge on the development, otherwise incentivised

348 financially. The slow down and decline of growth reflects the challenges faced as resources are

349 consumed. In the case of $\mathrm{CO}_{2}$ storage, the highest quality reservoirs with the largest structural traps

350 will be used before more marginal sites, e.g., in less permeable reservoirs with smaller traps.

351 While individual trajectories are of interest in considering a particular development pathway,

352 graphs showing these trajectories in the context of the tradeoffs between storage rate and resource

353 base provide more general information about the plausibility of the scenarios under consideration.

354 These figures are computed for the 'EU Member State Scenarios', 'UK Domestic Scenarios' and the

355 'EU + UK Scenarios', by finding a range of growth rates and storage resources required for a fixed

3562050 storage rate target (Figure 4). We represent individual scenarios with points on the graph (red

357 point in Figure 4). 


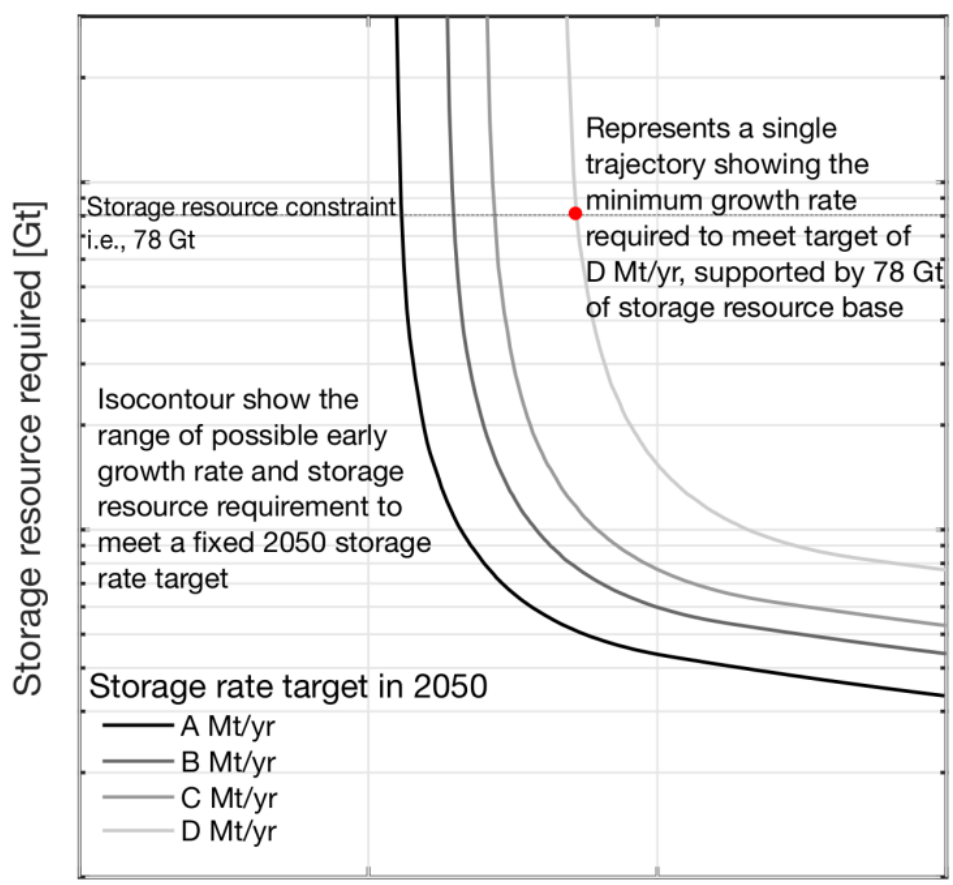

Growth Rate [\%]

359 Figure 4: An example of a tradeoff graph between post-2030 growth rates and the storage resource 360 required to support that growth. The thick grey lines are isocontours of storage rate targets in 2050.

361 The coloured point corresponds to a single trajectory, i.e., Fig. 3. Note that this is illustrative, and we 362 have kept numbers off of the axes, but the vertical axis is logarithmic and the horizontal axis linear.

\subsection{EU Member State Scenarios}

Storage rate target scenarios ranging from 80-330 $\mathrm{MtCO}_{2} \mathrm{yr}^{-1}$ in 2050 have been outlined by the European Commission ${ }^{9}$ and Shell International B.V. ${ }^{13}$ (Table 1). Currently announced plans for carbon capture and storage within EU member states are commensurate with storing $126 \mathrm{Mt}$ of $\mathrm{CO}_{2}$

368 cumulatively by $2030^{14,15}$ and we use this as the starting point for modelled trajectories (black marker 369 at 2030 on the cumulative graph in Figure 5). We show growth in annual injection rate from 2030 370 onwards at a range of rates from 9.5\% - 17.2\% in Figure 5 and values are reported in Table 3. The range of minimum rates to achieve EU1-4 (80 - $330 \mathrm{MtCO}_{2} \mathrm{yr}^{-1}$ in 2050) are 9.5\% - 14.7\% (green curves in Figure 5). These depend on the existence of a storage resource base at the maximum permitted in our model, $88 \mathrm{Gt}$, the resource currently estimated to be available in the EU including onshore storage resources ${ }^{21,22,24}$. However, given that current storage resource estimates are 
377 Figure 5), albeit sustained for much shorter periods. The inflection years (black dots on the rate graph 378 in Figure 5) indicate the points where the growth rate diverges from the exponential trend and there are dashed lines thereafter to emphasize that these trajectories are not predictive.

380
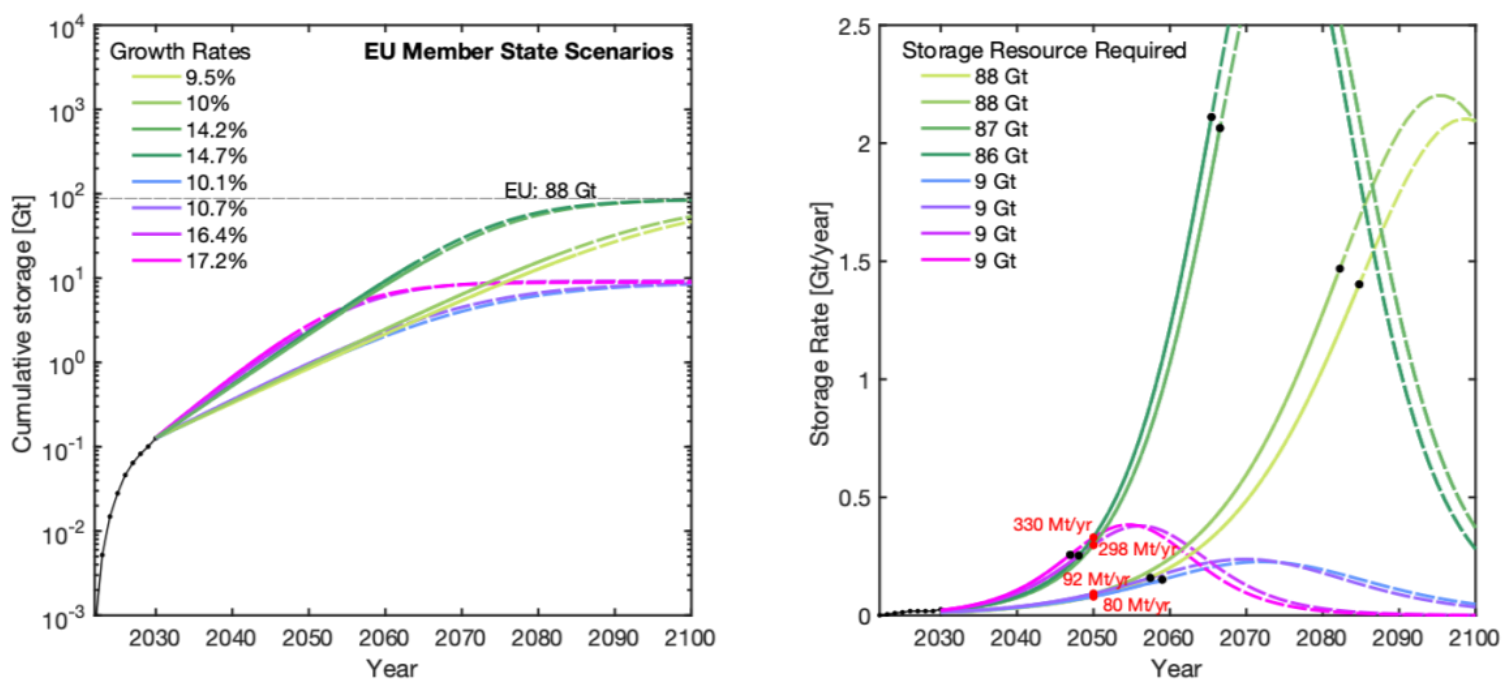

381 Figure 5: (Left) Cumulative $\mathrm{CO}_{2}$ storage as a function of time for EU Member State scenarios. (Right)

382 EU member state $\mathrm{CO}_{2}$ storage rate as a function of time for various growth scenarios. We compare

383 the range of growth rates required to meet storage rate targets of EU1-4 (80 - $\left.330 \mathrm{MtCO}_{2} \mathrm{yr}^{-1}\right)$,

384 indicated by the red points, at two storage resource bounds: $88 \mathrm{Gt}$ (entire EU) and $9 \mathrm{Gt}$ (10\% of

385 current best estimate). Model parameters are provided in Table 3.

The range of possible initial growth rate and storage resource base combinations needed to achieve 2050 targets are shown with isocontours in Figure 6. The hyperexponentially distributed isocontours indicate the pattern where the higher the initial growth rate reached by 2030, the lower the storage resource requirement to support that given growth rate. The initial steep slopes of the isocontours indicate the rate of change in growth rate is very slow compared to the rate of change in storage resource requirement; this suggests the target is growth rate limited. For the horizontal portion of the curve, storage resource limitations occur where the rate of change in storage resource requirement is very minimal whilst the rate of change in growth rate is substantial. Points illustrate those particular scenarios shown in Figure 5 where growth rates are minimised making use of either all (green points) or just 10\% of the estimated storage resource base (purple points). When constrained at $88 \mathrm{Gt}$, all of the 2050 targets required sustained annual growth of greater than $9.5 \%$, with the more ambitious targets (EU3 and EU4) requiring over 14\% average annual growth for at least 20 years. While these rates are frequently seen over short timescales, sustaining them for multiple 
399 decades is unusual for energy technologies ${ }^{57}$. If only offshore storage resource is available in the EU,

400 the growth rate required to meet EU1-4 is within a similar range of $10 \%->15 \%$. Additionally, Figure 6

401 shows that if $<7 \mathrm{Gt}$ of $\mathrm{CO}_{2}$ storage resources is identified, then EU3 and EU4 become significantly

402 difficult to achieve from a growth rate perspective - rates of growth that are $>20 \%$ are ultimately

403 required. This is the case for EU1 and 2 if $<2$ Gt of storage resource is developed.

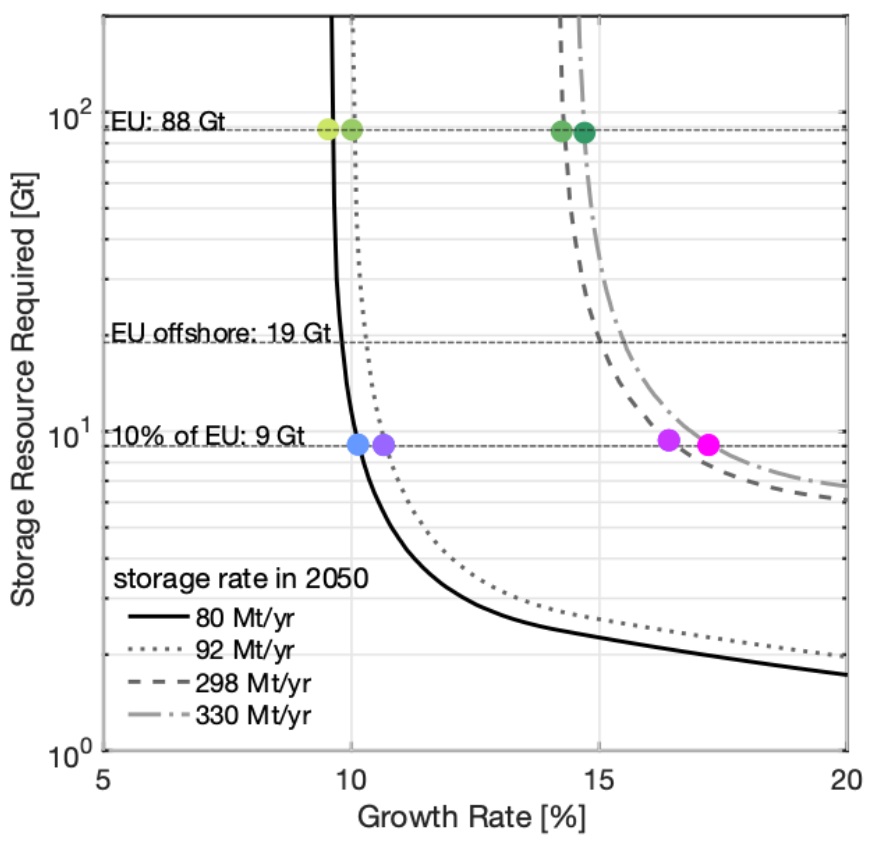

405 Figure 6: Tradeoff between storage resource requirements and early growth rates for EU member

406 state scenarios. The grey lines show isocontours of trajectories that meet storage rate targets in 2050.

407 The difference in the level of ambition between the targets for the range of growth rate and storage

408 resource requirement is illustrated; higher targets of $298 \mathrm{Mt} \mathrm{yr}^{-1}$ and $330 \mathrm{Mt} \mathrm{yr}^{-1}$ are more demanding

409 from a growth rate perspective. Higher growth rates are required when storage resource available is

$410 \quad$ limited (indicated by the purple points)

\begin{tabular}{c|cc}
$\begin{array}{c}\text { Growth } \\
\text { rate [\%] }\end{array}$ & $\begin{array}{c}\text { Storage resource } \\
\text { required [Gt] }\end{array}$ & $\begin{array}{c}\text { Storage rate target } \\
\text { achieved }\end{array}$ \\
\hline 9.5 & 88 & EU1 \\
10 & 88 & EU2 \\
14.2 & 87 & EU3 \\
14.7 & 86 & EU4 \\
10.1 & 9 & EU1 \\
10.7 & 9 & EU2
\end{tabular}




\begin{tabular}{l|ll}
16.4 & 9 & EU3 \\
17.2 & 9 & EU4
\end{tabular}

411 Table 3: A summary of modelled growth scenarios details which corresponds to coloured lines in Fig.5

412 and dots in Fig.6.

413 3.2 UK Domestic Scenarios

414 Storage rate target scenarios ranging from 75-175 $\mathrm{MtCO}_{2} \mathrm{yr}^{-1}$ in 2050 for the UK have been

415 recommended by the Committee on Climate Change and the Oil and Gas Authority ${ }^{11,12}$ (Table 1). The

416 currently planned CCS activities in the UK between 2022 and 2030 are to have stored a cumulative of

$41781 \mathrm{MtCO}_{2}$ offshore ${ }^{14,15}$ (black marker at 2030 on the cumulative graph in Figure 7). Figure 7 shows

418 trajectories from 2030 with annual growth in injection rates between 10.9\%-15.1\% meeting the

419 storage rate targets of the UK for 2050. Achieving the UK government's lowest carbon storage rate

420 target of $75 \mathrm{MtCO}_{2}$ year-1 (UK1) requires a minimum annual growth rate of $10.9 \%$ (yellow curve in Fig.

421 7) achieved when dependent upon the maximum resource base allowed, $78 \mathrm{Gt}$. This rises to $12.8 \%$ for

422 UK2 (130 $\left.\mathrm{MtCO}_{2} \mathrm{yr}^{-1}\right)$ and 14\% to reach the most aggressive target of $175 \mathrm{MtCO}_{2}$ year-1 (UK3) in 2050.

423 In contrast, limiting the resource base to just $10 \%$ of the currently estimated 88 Gt results in

424 minimum growth rates increasing to $11.4 \%, 13.7 \%$ and $15.1 \%$ to meet UK1-3, respectively. Table 4

425 provides a summary of these values for the UK domestic scenarios.
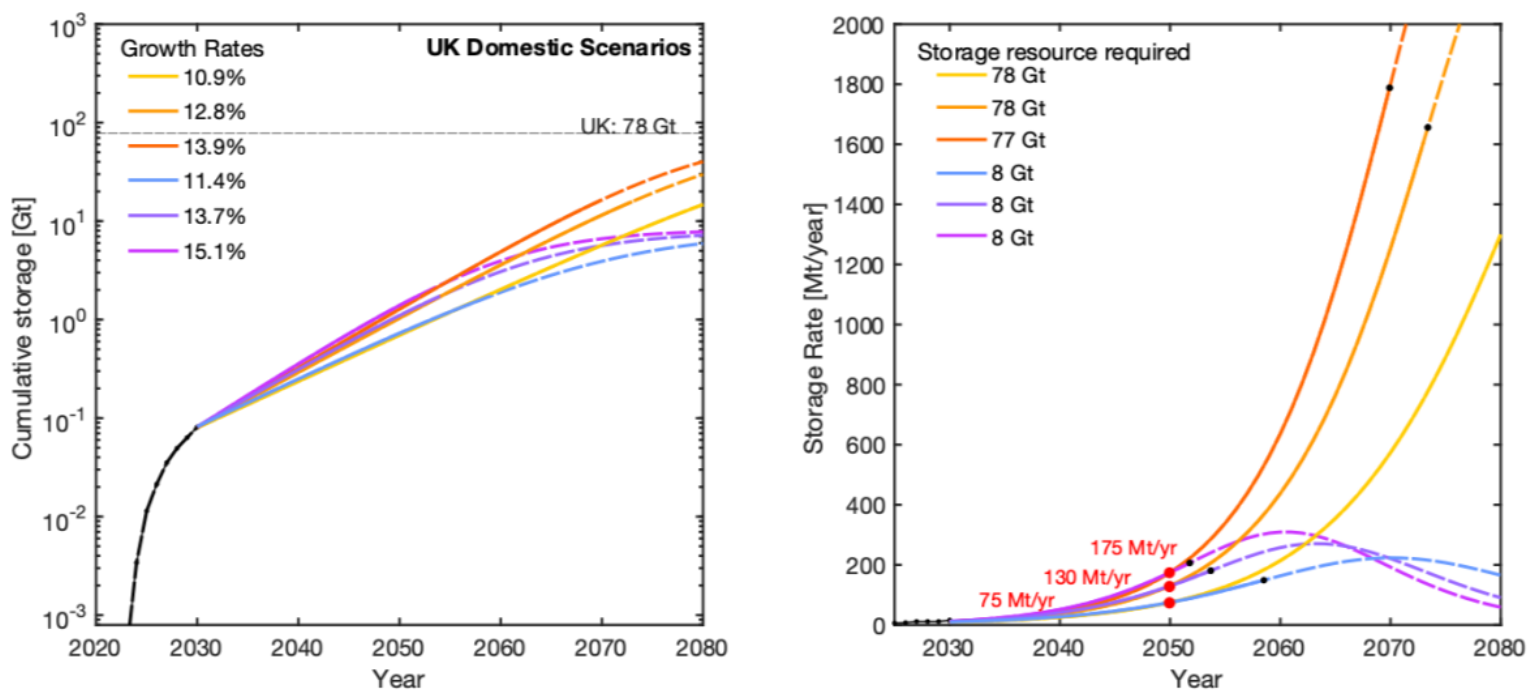

427 Figure 7: (Left) Cumulative $\mathrm{CO}_{2}$ storage for the UK domestic scenarios. (Right) $\mathrm{CO}_{2}$ storage rate for the 428 UK domestic scenarios. We compare the range of growth rates required to meet storage rate targets 429 of UK1-3 (75 - $175 \mathrm{MtCO}_{2} \mathrm{yr}^{-1}$ ), indicated by the red points, at two storage resource bounds: 78Gt (UK 430 offshore) and $8 \mathrm{Gt}$ (10\% of current best estimate). 
432 to trajectories shown in Figure 7. All of the scenarios (orange and purple points) require sustained

433 annual growth between $11 \%$ - 15\% regardless of the available storage resource base (78 Gt or $8 \mathrm{Gt}$ ).

434 The difference in growth rate requirement illustrated by the purple and orange points suggest that 435 the effect of storage resource limitation is more significant for the target of UK3. For all targets to be 436 feasible from a growth rate perspective, at least $4 \mathrm{Gt}$ of storage resource must be developed in the 437 UK.

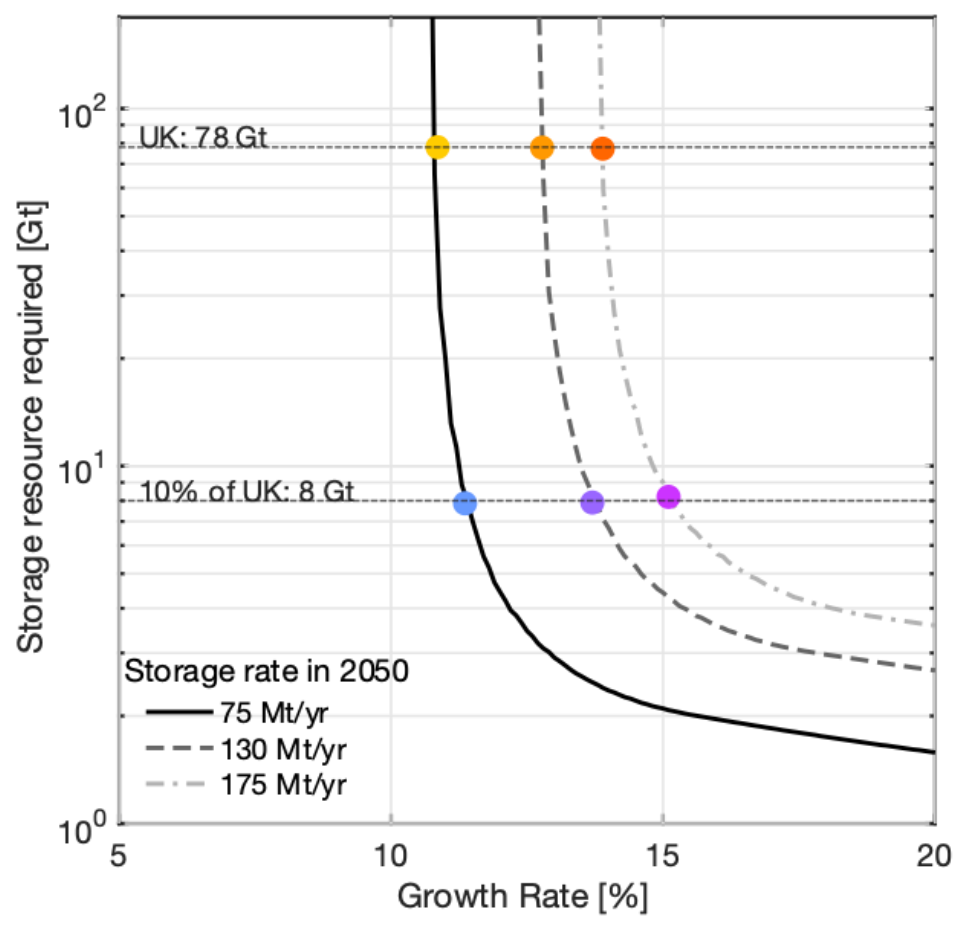

439 Figure 8: Tradeoff between storage resource requirements and early growth rates for UK domestic 440 scenarios. The solid grey lines show the storage resource required as a function of post-2030 growth 441 rates to reach the storage rate targets in 2050.

\begin{tabular}{c|cc}
$\begin{array}{c}\text { Growth } \\
\text { rate [\%] }\end{array}$ & $\begin{array}{r}\text { Total storage resource } \\
\text { required [Gt] }\end{array}$ & $\begin{array}{c}\text { Storage rate target } \\
\text { achieved }\end{array}$ \\
\hline 10.9 & 78 & UK1 \\
12.9 & 78 & UK2 \\
13.9 & 78 & UK3 \\
11.4 & 8 & UK1 \\
13.7 & 8 & UK2 \\
15.1 & 8 & UK3
\end{tabular}


Table 4: A summary of the results for growth scenarios of the UK domestic model, each corresponds

443 to the colour lines in Fig.7 and dots in Fig.8.

The tradeoff graph for the combined scenarios (Figure 9) illustrates the minimum growth rates bounded by the available storage resource in the UK (78 Gt), the Norwegian storage resource

447 (94 Gt), and the UK and Norway combined storage resource (172 Gt). The higher the storage rate 448 target, the higher the minimum growth rate necessary to achieve the target. Notably, the range of 449 minimum growth rates illustrated in Figure 9 is between 10.3\%-14.8\% depending on the size of the 450 supporting resource base (Table 5). Combining storage resources from the UK and Norway does not significantly impact the growth rate requirements for scaleup trajectories. The requirements are primarily driven by the 2050 rate targets and are not limited by the availability of storage resources.

The storage resource base of the UK and Norway are sufficiently large that limits imposed by the geology to scaleup would only emerge if there were major overestimates in the current resource assessment. In the case where we limit the resource to $17 \mathrm{Gt}$, or $10 \%$ of current estimates, the combined resource base of both the UK and Norway are needed to accommodate all of the injection rate targets. A smaller storage resource base must also be compensated by higher initial rates of growth. Around half of the targets depend on sustained annual growth of $15 \%$ or greater. For the lower storage rate targets, i.e., Group A-B targets in Figure 9, the demands on the injection growth rate are decreased by multiple percentage points when the combined resource base is available compared with that of either the UK or Norway alone. that may be considered plausible or otherwise of interest to explore. We illustrate an example for a conservative rate target in Figure 9 of $92 \mathrm{Mt} \mathrm{yr}^{-1}$ in 2050. This target could be achieved by sustaining annual growth in injection at the current global average of 8.6\% (red point in Figure 9) whereby cumulative storage of $1.1 \mathrm{Gt}$ would be achieved by 2050 . Alternatively, a range of trajectories

467 dependent on the existence of $10 \%$ or less of the currently estimated resource base can be made with 468 sustained annual growth of less than 10\% (bold red line in Figure 9). These types of considerations 469 and constraints are computationally efficient and could be easily incorporated into energy systems 470 models of climate change mitigation. 

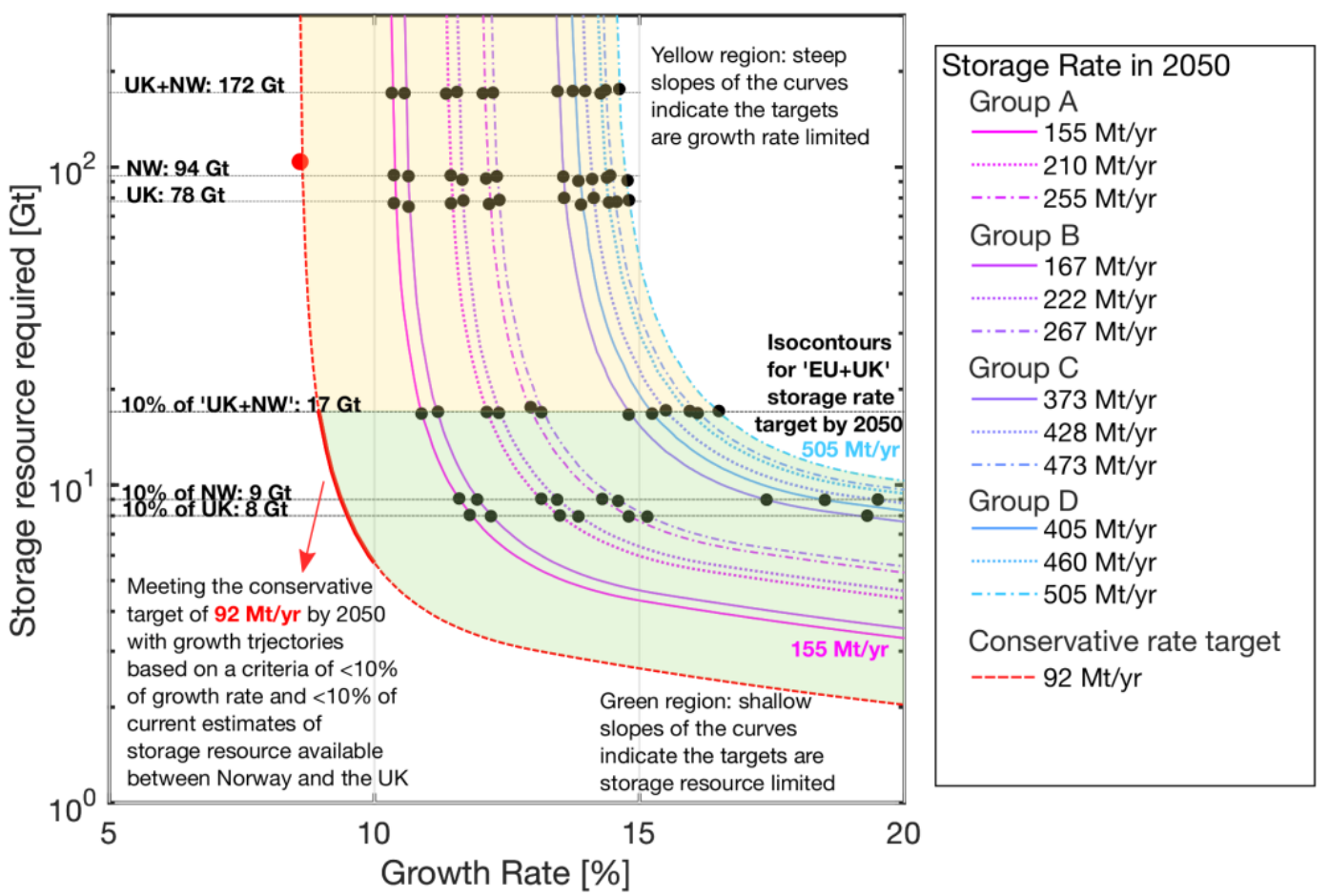

473

Growth Rate [\%]

474 Figure 9: Tradeoff between storage resource requirement and growth rates for the four groups of

475 combined "EU + UK" storage targets for 2050 indicated by the legend (See Tables 2 for associated

476 targets). The black points correspond to minimal growth rates subject to various storage resource

477 constraints (See Table 5 for values of minimum growth rates).

478

Storage resource Range of minimum Range of minimum Range of minimum Range of minimum

Requirement [Gt] growthratesfor growthratesfor growthratesfor growthratesfor

Group A [\%] Group B [\%] Group C [\%] Group D [\%]

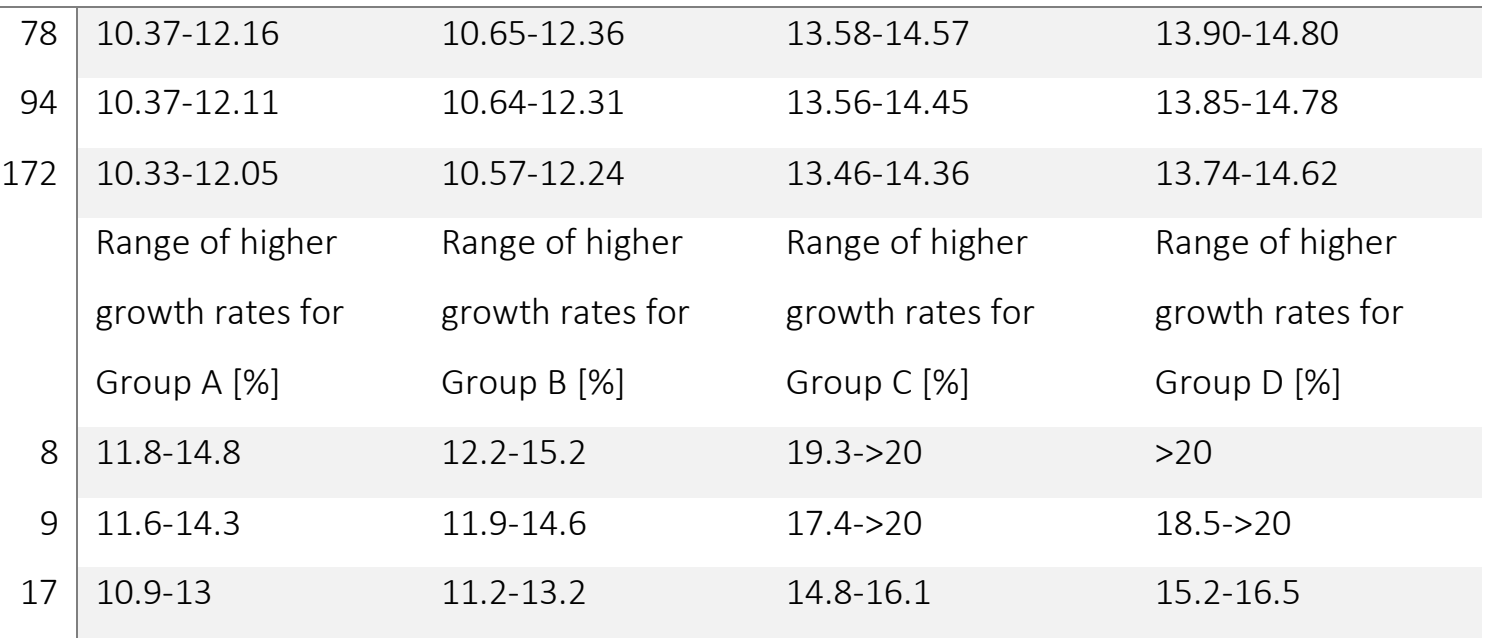


Table 5: A summary of the results for growth scenarios identified for 'EU+UK' storage targets

480 requiring the entire and $10 \%$ of storage resource available offshore of UK, Norway and combined

481 storage resource.

\section{DISCUSSION}

Plans for the deployment of CCS by the European Union and the UK imply sustained annual

484 growth in $\mathrm{CO}_{2}$ storage rates of at least 9\%, and up to 15\% from 2030 to 2050 (Figure 5 and 7). Others

485 have shown that the scale of subsurface engineering required is precedented ${ }^{57}$. Indeed, oil production

486 from 1901 sustained a 15\% average annual growth for 40 years ${ }^{58}$. However, market conditions driving

487 the expansion of the demand for oil, which include the first World War, and relatively few limitations

488 ensuring safety or environmental standards, reveal the magnitude of incentivisation required to

489 achieve such growth ${ }^{59,60}$.

The storage resource of the UK and Norway, alone or combined, appear sufficiently abundant to serve as a regional $\mathrm{CO}_{2}$ storage hub for the European continent (Figure 9). Significant limits imposed by geology only emerge if development is restricted to less than $10 \%$ of current estimates of

493 the resource base. Even then, there is a range of significant 2050 rate targets that can be met without unduly high growth rates.

This analysis provides a framework to develop technology roadmaps including the scaleup of

$496 \mathrm{CO}_{2}$ storage within realms of plausible ranges of growth rate and storage resource base. For the last

49720 years, the global annual average scaleup of $\mathrm{CO}_{2}$ storage rates is at around $8.6 \%{ }^{20}$. Using this as a

498 demonstrated benchmark, a trajectory with 8.6\% annual growth from 2030 onwards for the European

499 Continent, dependent on a combined storage resource base of $104 \mathrm{Gt}$ is evidently plausible. This

500 scenario translates into a 2050 regional storage rate target of $92 \mathrm{MtCO}_{2} \mathrm{yr}^{-1}$ (red dashed curve in

501 Figure 9) and cumulative storage of $1.1 \mathrm{Gt}$. This rate target can also be met with a range of scenarios

502 that can be achieved depending on less than $10 \%$ annual growth and less than $10 \%$ of the currently

503 identified resource base.

This analysis also points to the period between 2021 and 2030 as a critical window for Europe to establish large-scale CCS operations. It has assumed storage rates starting in 2030 based on

506 published plans for the coming decade. However, delays or shortfalls in achieving these plans will 507 place larger demands on the scaleup rates required and the storage resource base needed to support 508 storage rate targets. 
510 In this study, we evaluate the scaleup of geological $\mathrm{CO}_{2}$ storage identified in European climate

511 change mitigation plans. We show that all storage targets require historically high rates of growth;

512 minimum average annual growth in injection capacity from 2030 through 2050 needs to achieve 10\%-

$51315 \%$ to meet European targets. In contrast, $\mathrm{CO}_{2}$ storage plans are not limited by current estimates of

514 the resource base available and can be accommodated by the offshore reservoirs of the UK or Norway

515 alone. Storage resource limitations will only occur if the resource base has been significantly

516 overestimated, i.e., around $10 \%$ or less of current best estimates. In such a case, higher rates of near-

517 term growth of $11 \%-17 \%$ and the combined resources of the UK and Norway are ultimately required.

518 Comparing these modelled growths with the production growth rates achieved by the petroleum

519 industry reveals that wartime-like mobilisation of supply chain and manufacturing capacity may be

520 required to meet published storage targets in Europe. Finally, we show how the logistic modelling

521 framework can be used for constraining the deployment of $\mathrm{CO}_{2}$ storage in energy systems models that

522 are subject to conservative criteria and illustrate this by identifying a range of conservative storage rate

523 target scenarios, i.e., $92 \mathrm{MtCO}_{2} \mathrm{yr}^{-1}$ in 2050.

526 Funding for this work was provided by the Engineering and Physical Sciences Research Council.

Y.Z. and S.K. conceived the study. Y.Z. performed the research and led the writing of the manuscript.

529 C.Z. and Y.Z. developed the computer code. All authors contributed to the writing of the manuscript.

\section{COMPETING INTERESTS}

531 The authors declare no competing interests.

1. Haszeldine, S. R. Carbon capture and storage: how green can black be? Science 325, 1647-1652 (2009). https://doi.org/10.1126/science.1172246

2. Pires, J. C. M., Martins, F. G., Alvim-Ferraz, M. C. M., \& Simões, M. Recent developments on carbon capture and storage: An overview. Chemical Engineering Research and Design 89, 1446-1460 (2011). https://doi.org/10.1016/j.cherd.2011.01.028

3. Bui, M. et al. Carbon capture and storage (CCS): The way forward. Energy and Environmental Science 11, 10621176 (2018). https://doi.org/10.1039/c7ee02342a

4. IPCC Climate Change 2014: Synthesis Report. Contribution of Working Groups I, II and III to the Fifth Assessment 
Report of the Intergovernmental Panel on Climate Change (eds Edenhofer, O. et al.) (IPCC, 2014).

5. Koelbl, B. S., van den Broek, M. A., Faaij, A. P. C., \& van Vuuren, D. P. Uncertainty in Carbon Capture and Storage (CCS) deployment projections: A cross-model comparison exercise. Climatic Change 123(3-4), 461-476 (2014). https://doi.org/10.1007/s10584-013-1050-7

6. Rogelj, J., Luderer, G., Pietzcker, R. C., Kriegler, E., Schaeffer, M., Krey, V., Riahi, K. Energy system transformations for limiting end-of-century warming to below $1.5^{\circ} \mathrm{C}$. Nature Climate Change 5, 519-527. (2015). https://doi.org/10.1038/nclimate2572

7. IPCC Global Warming of $1.5^{\circ} \mathrm{C}$. An IPCC Special Report on the impacts of global warming of $1.5^{\circ} \mathrm{C}$ above preindustrial levels and related global greenhouse gas emission pathways, in the context of strengthening the global response to the threat of climate change, sustainable development, and efforts to eradicate poverty (eds MassonDelmotte, V. et al.) (IPCC, 2018).

8. Oil information: Overview (IEA, 2020) https://www.iea.org/reports/oil-information-overview

9. A Clean Planet for all: A European strategic long-term vision for a prosperous, modern, competitive and climate neutral economy. (European Commission, 2018)

10. Ten Point Plan (UK Government, 2020).

11. UKCS Energy Intergration FInal Report. Annex 2. Carbon Capture and Storage (Oil and Gas Authority, 2020).

12. Net Zero - The UK's Contribution to Stopping Global Warming (Committee on Climate Change, 2019).

13. Shell Sky Scenario (Shell International B.V., 2018).

14. Global Status of CCS: 2020 (Global CCS Institute, 2020).

15. Global CCS Projects (International Association of Oil and Gas Producers, 2020).

16. $\mathrm{CO}_{2}$ Storage Resources Management System (Soceity of Petroleum Engineers, 2017).

17. Budinis, S., Dowell, N. Mac, Krevor, S., Dixon, T., Kemper, J., \& Hawkes, A. Can Carbon Capture and Storage Unlock “Unburnable Carbon”? Energy Procedia 114, 7504-7515 (2016). https://doi.org/10.1016/j.egypro.2017.03.1883

18. Consoli, C. P., \& Wildgust, N. Current Status of Global Storage Resources. Energy Procedia 114, 4623-4628 (2017). https://doi.org/10.1016/j.egypro.2017.03.1866

19. Global Storage Resource Assessment - 2019 Update (Pale Blue Dot Energy, 2020).

20. Zahasky, C., \& Krevor, S. Global geologic carbon storage requirements of climate change mitigation scenarios. Energy Environment. Sci. 13, 1561-1567 (2020). https://doi.org/10.1039/D0EE00674B

21. Assessing European Capacity for Geological Storage of Carbon Dioxide. EU GeoCapacity Consortium (GeoCapacity, 2009).

22. State of Play on CO2 Geological Storage in 28 European Countries. CGS Europe Report No. D2.10. pp. 1-89 (Rütters, H. and the CCS Europe Partners., 2013).

23. Strategic UK CCS Storage Appraisal (Energy Technologies Insitute, 2016).

24. CO2StoP Final Report: Assessment of CO2 storage potential in Europe (Geological Survey of Denmark and Greenland, 2014)

25. $\mathrm{CO}_{2}$ Storage Atlas Norwegian North Sea (Norwegian Petroleum Directorate, 2019).

26. Communication From The Comission To The European Parliament, The Council, The European Economic and Social Committee and The Committee of the Regions on the Future of Carbon Capture and Storage in Europe. COM(2013) 180 final (European Comission, 2013)

27. Donda, F., Volpi, V., Persoglia, S., Parushev, D. $\mathrm{CO}_{2}$ storage potential of deep saline aquifers: The case of Italy. International Jounral of Greenhouse Gase Control 5, 327-335 (2011). https://doi.org/10.1016/j.ijggc.2010.08.009 
options. (2012).

29. Lothe, A., Emmel, B., Bergmo, P., Mortensen, G. M., Frykman, P. A first estimation of storage potential for selected aquifer cases. (2014)

30. CCS in Energy and Climate Scenarios. (IEAGHG, 2019)

31. Iyer, G. et al. Diffusion of low-carbon technologes and the feasibility of long-term climate targets. Technological Forecasting and Social Change 90, 103-118 (2015)

32. Larson, E. et al. Net-Zero America: potential pathways, infrastructure, and impacts. Interim report, Princeton Unicersity. (2020)9

33. Peterhead CCS project FEED Summary Report for Full CCS Chain (Shell, 2016)

34. Peterhead CCS project Conceptual Completions \& Well Intervention Design Report (Shell, 2014)

35. Peterhead CCS project Geochemical Reactivity Report (Shell, 2015)

36. Peterhead CCS project Dynamic Reservoir Modelling Report (Shell, 2014)

37. Peterhead CCS project Storage Development Plan (Shell, 2015)

38. Peterhead CCS Cost Estimate Report (Shell, 2016)

39. Peterhead CCS project Permits and Consents Register (Shell, 2016)

40. Peterhead CCS project Summary of Bidder considerations in arriving at a Final Invenstment Decision (Shell, 2016)

41. Peterhead CCS project Stateholder and Public Engagement and Communications (Shell, 2016)

42. Bachu, S. Review of $\mathrm{CO}_{2}$ storage efficiency in deep saline aquifers. International Journal of Greenhouse Gas Control 40, 188-202 (2015). https://doi.org/10.1016/j.ijggc.2015.01.007

43. Bradshaw, J. et al. $\mathrm{CO}_{2}$ storage capacity estimation: issues and development of standards. International Journal of Greenhouse Gas Control 1, 62-68 (2007). https://doi.org/10.1016/S1750-5836(07)00027-8

44. Budinis, S., Krevor, S., Dowell, N. Mac, Brandon, N., \& Hawkes, A. An assessment of CCS costs, barriers and potential. Energy Strategy Reviews 22, 61-81 (2018). https://doi.org/10.1016/j.esr.2018.08.003

46. Lockwood, M. The political sustainability of climate policy: The case of the UK Climate Change Act. Global Environmental Change 23, 1339-1348 (2013). https://doi.org/10.1016/j.gloenvcha.2013.07.001

47. UK Government. UK becomes first major economy to pass net zero emissions law. https://www.gov.uk/government/news/uk-becomes-first-major-economy-to-pass-net-zero-emissions-law (2019).

48. Tjernshaugen, A. The growth of political support for $\mathrm{CO}_{2}$ capture and storage in Norway. Environmental Politics 2, 227-245 (2011). https://doi.org/10.1080/09644016.2011.551029

49. Anthonsen, K. L. et al. $\mathrm{CO}_{2}$ storage potential in the Nordic region. Energy Procedia 37, 5080-5092 (2013). https://doi.org/10.1016/j.egypro.2013.06.421

50. Hubbert, M. K. Nuclear energy and the fossil fuels. Drilling and Production Practice 1956, 7-15 (1956).

51. Grübler, A., Nakićenović, N., \& Victor, D. G. Dynamics of energy technologies and global change. Energy Policy 5, 247-280 (1999). https://doi.org/10.1016/S0301-4215(98)00067-6

52. Brandt, A. R. Testing Hubbert. Energy Policy 35, 3074-3088 (2007). https://doi.org/10.1016/j.enpol.2006.11.004

53. Rutledge, D. Estimating long-term world coal production with logit and probit transforms. International Journal of Coal Geology 85, 23-33 (2011). https://doi.org/10.1016/j.coal.2010.10.012

54. Höök, M., Li, J., Oba, N., \& Snowden, S. (2011). Descriptive and Predictive Growth Curves in Energy System Analysis. Natural Resources Research 20, 103-116 (2011). https://doi.org/10.1007/s11053-011-9139-z

55. Brandt, A. Review of mathematical models of future oil supply: Historical overview and synthesizing critique. 
56. Ringrose, P. S., \& Meckel, T. A. Maturing global CO2 storage resources on offshore continental margins to achieve 2DS emissions reductions. Sci Rep 9, 17944 (2019). https://doi.org/10.1038/s41598-019-54363-z

57. Wilson, C., Grubler, A., Bauer, N., Krey, V., \& Riahi, K. Future capacity growth of energy technologies: are scenarios consistent with historical evidence? Climate Change 118, 381-395 (2013). https://doi.org/10.1007/s10584-012$\underline{0618-y}$

58. World Primary Energy Production (Theshiftdataportal, 2020). https://www.theshiftdataportal.org/energy/primaryenergy?chart-type=line\&chart-types=stacked \&chart-types=stacked-percent \&chart-types=pie \&charttypes=line\&chart-types=ranking\&disable-en=false\&energy-families=Oil\&energy-families=Gas\&energyunit=Mtoe\&gdp-unit=GDP\%20(constant\%202010\%20US\%24)\&group-names=World\&is-

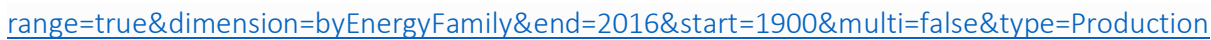
Geological Society Special Publication 465, 1-24 (2018). https://doi.org/10.1144/SP465.23 